\title{
The Maternal Behavior Rating Scale
}

Gerald Mahoney, Amy Powell, University of Michigan, and Iris Finger, University of California-Los Angeles

This investigation presents data on a seven-item short form of the Maternal Behavior Rating Scale, which is a global rating scale designed to assess the quality of maternal interactive behavior with young mentally retarded children. Seven items were used to assess the interactive behavior of a sample of 60 mothers while they were playing with their mentally retarded children who were either 1, 2, or 3 years of age. A factor analysis of the seven items revealed two independent parameters of maternal behavior, child orientedness/pleasure, and control. A least squares regression procedure indicated that the two factors accounted for $20 \%$ of the variability in children's level of mental development. These results closely approximated those obtained with the 18 -item version of this scale.

Currently the activities of several early intervention programs for severely handicapped children are focusing on the quality of interaction between mothers and their children (Assael, 1983). A variety of intervention procedures are being designed to promote patterns of interaction between mothers and their children that are likely to foster children's development (Bromwich, 1978; MacDonald \& Gillette, 1984; Mahoney \& Powell, 1984). Although this approach is consistent with contemporary models of infant development (Sameroff \& Chandler, $1975)$, it is generally difficult to evaluate its effects. One problem is the lack of procedures that can feasibly be used in intervention programs to quantify critical dimensions of maternal interactive behavior. The purpose of the investigation reported here was to develop a short form 
of the Maternal Behavior Rating Scale (MBRS; Mahoney, Finger, \& Powell, 1985) that could be used conveniently by intervention programs as a means for assessing program impact on maternal interactive behavior.

The MBRS is a series of 18 items compiled from various global maternal rating scales reported in the child development literature. Table 1 is a list of the scales that were used as a basis for developing the MBRS. For the most part the scale includes only items that other investigators have found to be related to variability in children's rate of intellectual, language, or social development. Efforts were made to exclude items that assessed dimensions of maternal behavior that had been reported to be unrelated to the development of normal children.

In our initial study with this scale (Mahoney, Finger, \& Powell, 1985), we attempted to determine whether and/or how ratings of maternal behavioral syle might be related to variability in mental development among a group of 60 organically impaired, mentally handicapped children including 20 children each at 12, 24, and 36 months of age. Each mother and child were videotape-recorded in their home while playing on their living room floor with a set of toys that we provided. These videotapes were then used as a basis for rating the 18 items on the MBRS. Each item was rated on a 5-point Likert scale. Interrater agreement within 1 scale point ranged from $93 \%$ to $100 \%$ and averaged $98 \%$ for all 18 items.

In our analyses of these maternal ratings we found that most of the items had mean ratings for the three age groups that fell within the middle range of the 5-point scale (2.78-3.75). Four items, Responsivity, Comfort, Effectiveness, and Patience, had high average ratings (3.954.15); and only one item, Physical Stimulation, had low average ratings (1.62). As expected, we found that the magnitude of the ratings varied significantly across the three age levels, with mothers of 12 -month-olds being more physical but less sensitive to their children's interests and state and less appropriate in their stimulation than mothers of 24- and 36-month-olds. Mothers of 36-month olds were more responsive, permissive, and played more appropriately than mothers of 12-month olds.

Because many of the items on the scale were conceptually similar to each other and had a high degree of intercorrelation, the set of scale items was factor analyzed to reduce it to a smaller set of maternal behavior variables. The results of this procedure yielded three independent factors. The first factor, Child Oriented/Maternal Pleasure, loaded highly on items that reflected the orientation of mothers toward 
46, TOPICS IN EARLY CHILDHOOD SPECIAL EDUCATION 6:2

Table 1. Rating Scales of Maternal Behaviors

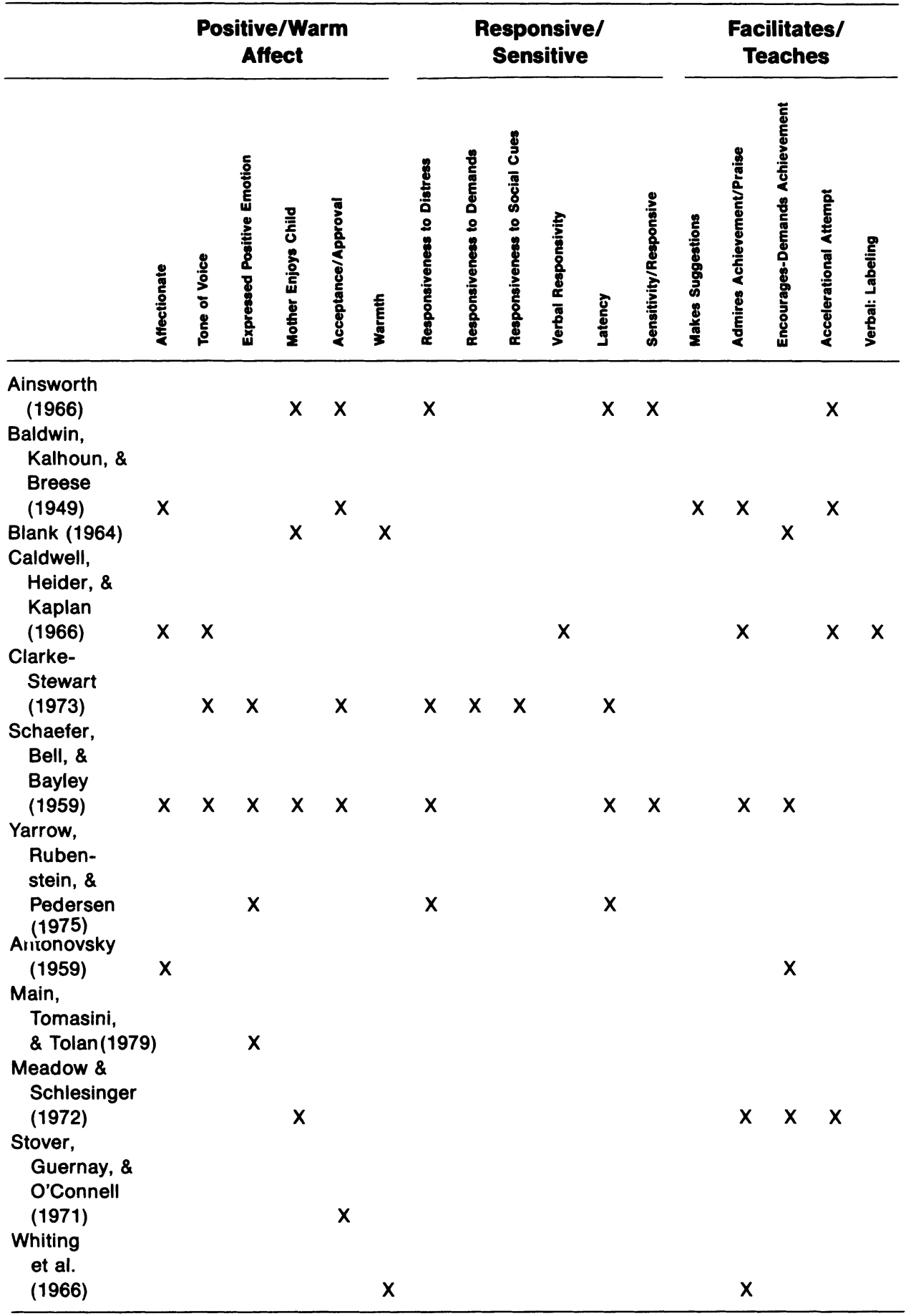




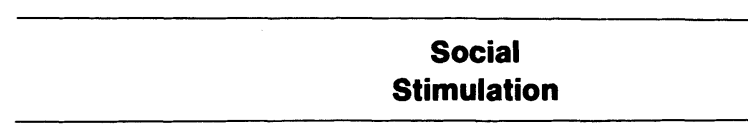

\begin{tabular}{c}
$\begin{array}{c}\text { Controlling/ } \\
\text { Negative }\end{array}$ \\
\hline
\end{tabular}
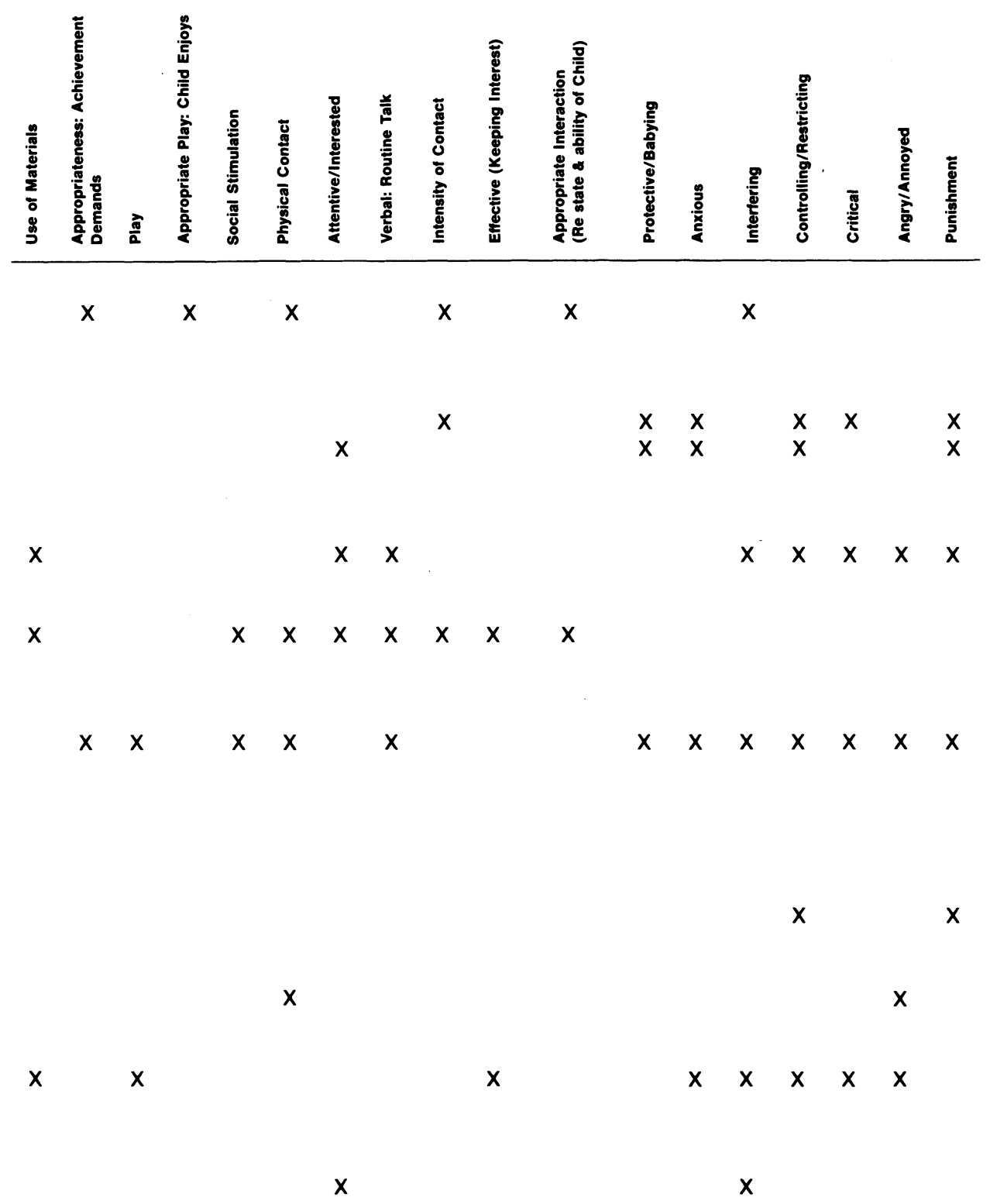
their children, as well as mother's apparent enjoyment. The second factor, Quantity of Stimulation, loaded highly on items reflecting the quantity of maternal stimulation during the play session. The third factor, Control, loaded highly on items that reflected maternal control, such as directiveness, achievement orientation, and sensitivity to child's interests. In general, the parameters of maternal behavior reflected by these factors were similar to the major maternal variables that have been identified as being related to the development of normal children (Clarke-Stewart, 1973; Yarrow, Rubenstein, \& Pedersen, 1975).

We derived factor scores for each of the mothers and used a least squares regression procedure to estimate the relationship between the maternal factors and children's developmental status relative to their age group as measured by the Bayley Mental Development Scale (Mental Development Index; MDI). The results of this analysis indicated that $23 \%$ of the variance in children's MDI was related to maternal style, with Child Oriented/Maternal Pleasure being related positively and Quantity of Stimulation and Control being related negatively to children's level of development across the three ages. These findings suggested that the maternal characteristics assessed by this scale may have significant implications for the development of mentally handicapped children.

The main problem in using the MBRS for assessing intervention effects is that it takes a considerable amount of time to use the scale and to achieve adequate reliability on each of the 18 items. In this investigation we attempted to identify a short form of the MBRS with psychometric properties similar to those of the original scale, both in terms of the characteristics of maternal behavior that are assessed and its concurrent relationship to children's developmental status.

\section{Methods}

\section{Subjects}

The sample included 60 mother-child dyads in which the children had been diagnosed as having medical or physiological conditions commonly associated with mental retardation (Grossman, 1973), but who did not have other major physical or sensory impairments. Ninety percent of the children had various forms of Down syndrome, and the remaining children had conditions such as William's syndrome and hydrocephaly. Subjects were recruited through a variety of resources 
including parent groups, newborn clinics, and infant intervention programs. Approximately $70 \%$ of the sample came from the Los Angeles area, while the remainder of the sample came from the Chicago area. Data were collected over a 3-year period between 1977 and 1980.

Table 2 lists several demographic characteristics of the sample. There were equal numbers of 12-, 24-, and 36-month-old children, of whom $57 \%$ were boys and $43 \%$ were girls. Most of the sample could be classified as middle class according to the Hollingshead Four Factor Index. Sixty percent of the mothers were Caucasian, 95\% were married, and $68 \%$ were homemakers.

\section{Procedures}

Data were collected by two research assistants in the homes of the subjects on one day that was divided into a morning and afternoon session. In the morning the child and mother were given time to become acquainted with the examiners, after which the Bayley Mental Development Scale was administered to the child. In the afternoon the mother and child were videotape-recorded while playing together on their living room floor. The subjects were instructed to play in any manner they chose, but to use only toys provided by the examiners, which included a xylophone, wooden blocks, stacking rings, nesting blocks, a pull toy, picture books, a toy bus with moveable wooden figures, and a play stove.

Each videotape was rated independently by two raters who had received 50 hours of training. The raters scored each of the 18 items of the MBRS on a 5-point Likert scale. When raters disagreed on the value assigned to an item, they discussed the item and arrived at a consensus rating. Interrater reliability as estimated by Pearson correlation coefficients was .79 immediately after training and .81 on a random sample of 15 dyads. Percentage of agreement within one scale point ranged from $93 \%$ to $100 \%$.

\section{Results}

The mean ratings and standard deviation for each of the 18 items are presented in Table 3. A principal axis procedure was used for factor analyzing the scale. The resulting factors had a Kaiser's Statistic of .96 and accounted for $72 \%$ of the variance. Since 12 of the 18 items loaded 
Table 2. Means and Standard Deviations by Children's Age Groups for Demographic Characteristics

\begin{tabular}{|c|c|c|c|c|c|c|c|c|}
\hline & \multicolumn{2}{|c|}{$\begin{array}{l}\text { One year } \\
(n=20)\end{array}$} & \multicolumn{2}{|c|}{$\begin{array}{l}\text { Two Years } \\
(n=20)\end{array}$} & \multicolumn{2}{|c|}{$\begin{array}{c}\text { Three Years } \\
(n=20)\end{array}$} & \multicolumn{2}{|c|}{$\begin{array}{c}\text { Total Sample } \\
\quad(n=60)\end{array}$} \\
\hline & $x$ & SD & $x$ & SD & $x$ & SD & $x$ & SD \\
\hline $\begin{array}{r}\text { Child's CA } \\
\text { (months) }\end{array}$ & 12.55 & 0.51 & 24.50 & 1.00 & 36.90 & 1.21 & 24.65 & 10.07 \\
\hline Bayley $\mathrm{DA}^{\mathrm{a}}$ & 7.25 & 1.36 & 15.10 & 2.61 & 19.30 & 2.96 & 13.88 & 5.57 \\
\hline $\begin{array}{l}\text { Mother's CA } \\
\text { (years) }\end{array}$ & 31.15 & 4.97 & 31.00 & 6.77 & 37.25 & 8.03 & 33.13 & 7.22 \\
\hline $\begin{array}{l}\text { Mother's Education } \\
\text { (years) } \\
\text { SES }\end{array}$ & 13.75 & 1.86 & 12.95 & 1.88 & 13.50 & 2.16 & 13.40 & 1.97 \\
\hline (Hollingshead) & 41.40 & 13.69 & 40.70 & 12.41 & 45.65 & 14.60 & 42.58 & 13.55 \\
\hline
\end{tabular}

${ }^{\text {a Developmental age }}$

highly on the first factor, this solution was rotated using a varimax procedure. The rotated solution yielded three orthogonal factors that are identified in Table 4 as Child Oriented/Maternal Pleasure, Quantity of Stimulation, and Control.

A series of additional factor analyses was conducted using the same statistical procedures, but selecting out various subsets of items. These analyses indicated that at least 16 items were required to replicate the three original factors, while as few as six items could be used to replicate two of the three factors. It was decided to identify the smallest set of maternal items that would replicate two of the three factors and yet maintain good statistical properties. The best solution from these analyses is presented in Table 5. The seven items included in the factor analysis were Enjoyment, Sensitivity to Interests, Sensitivity to State, Responsiveness, Appropriate Stimulation, Physical Stimulation, and Directiveness. The factor analysis of these items had a Kaiser's Statistic of .91 and accounted for $74 \%$ of the variance. The rotated solution yielded two orthogonal factors. Factor 1, which loaded highest on Enjoyment, Sensitivity to State, Responsiveness, and Appropriate Stimulation appeared to replicate Child Oriented/Maternal Pleasure. Factor 2, which loaded positively on Directiveness and Physical Stimulation and negatively on Sensitivity to Interests, generally replicated the original Control factor.

To determine whether this short form of the MBRS was related to variability in children's development we computed scaled factor scores for each of the mothers and estimated the concurrent relationship between Maternal Factors and children's MDI with the least squares 


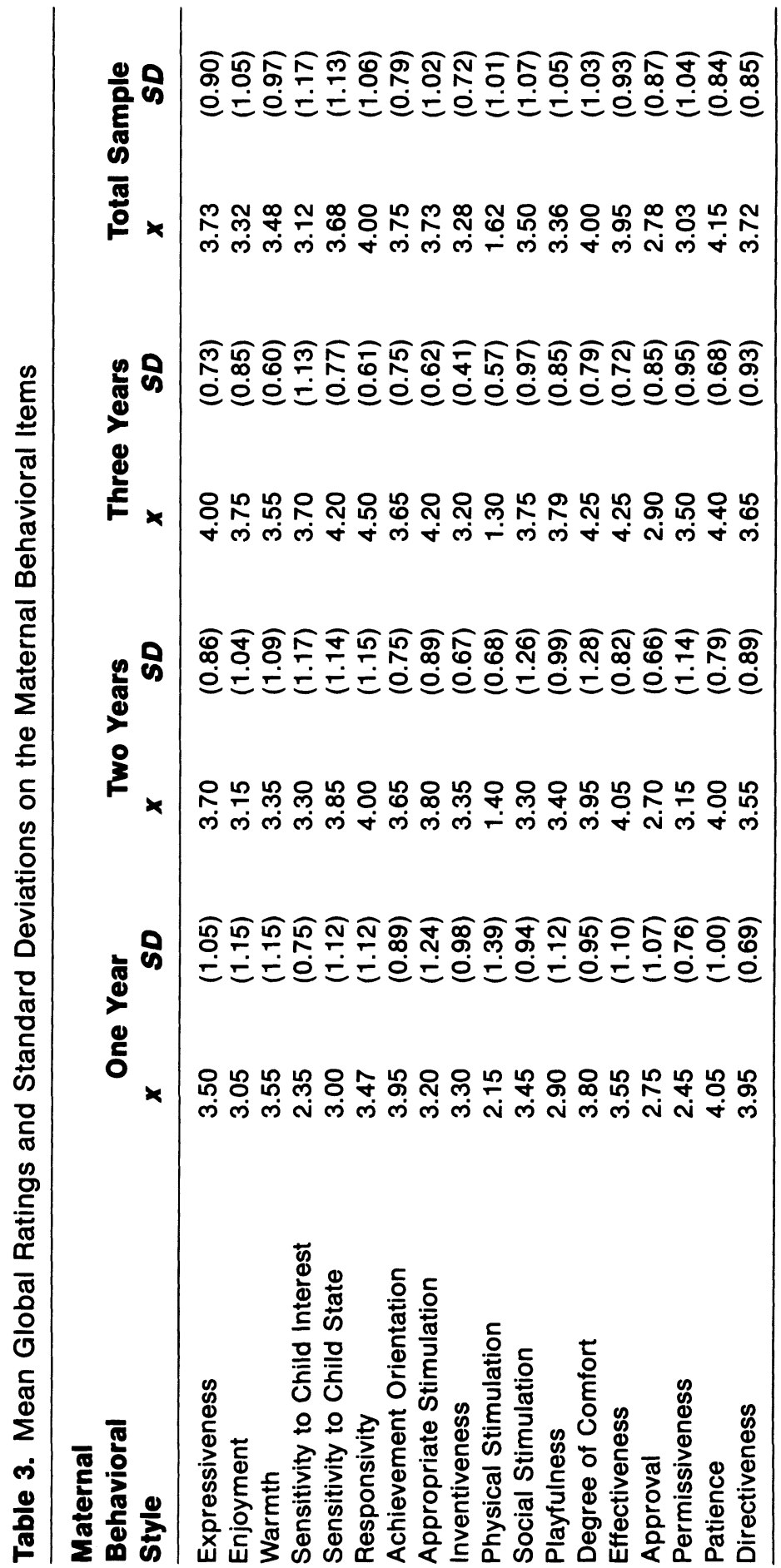


regression procedure. Since the conversion tables for determining the Mental Development Index (MDI) did not include scores below 50 or scores for children older than 30 months, a ratio MDI was calculated for each of the subjects (e.g., DA/CA $\times 100)$. These scores were then converted to standard scores by age group, so that each age group would have a mean of zero and standard deviation of one. This procedure enabled us to combine Bayley scores so that children's ranking in their own age group would be proportionally equivalent to their ranking in the total sample.

The regression model was used for estimating the variability in Bayley scores that was related to the maternal factors. It included the two maternal factors and two dummy grouping variables. Since the grouping variables could not account for variability in MDI because of the standardization procedure, the $R^{2}$ for this equation indicates the magnitude of the relationship between the maternal factors and MDI (Kerlinger \& Pedhazur, 1973). As indicated in Table 6, the results of this equation were significant $(p<.05)$, with the maternal factors accounting for $20 \%$ of the variance of MDI. The partial correlations indicated that

Table 4. Factor Analysis of Maternal Behavior Rating Scale

\begin{tabular}{|c|c|c|c|}
\hline Maternal Behavior & Factor $1^{n}$ & Factor $2^{b}$ & Factor $3^{c}$ \\
\hline Effectiveness & .84 & $\ldots$ & $\ldots$ \\
\hline Sensitivity to State & .82 & $\cdots$ & -.43 \\
\hline Degree of Comfort & .79 & $\cdots$ & $\cdots$ \\
\hline Appropriate Stimulation & .73 & $\cdots$ & $\cdots$ \\
\hline Enjoyment & .73 & .51 & $\ldots$ \\
\hline Responsiveness & .72 & $\ldots$ & -.34 \\
\hline Playfulness & .64 & .57 & $\cdots$ \\
\hline Approval & .62 & .28 & $\cdots$ \\
\hline Warmth & .39 & .79 & $\cdots$ \\
\hline Physical Stimulation & $\cdots$ & .78 & $\cdots$ \\
\hline Social Stimulation & .43 & .73 & $\ldots$ \\
\hline Inventiveness & .31 & .67 & $\cdots$ \\
\hline Expressiveness & .40 & .65 & $\cdots$ \\
\hline Patience & .46 & .54 & -.49 \\
\hline Directiveness & $\ldots$ & $\ldots$ & .88 \\
\hline Permissiveness & .30 & $\ldots$ & -.88 \\
\hline Sensitivity to Interests & .41 & $\cdots$ & -.79 \\
\hline Achievement Orientation & .43 & $\cdots$ & .67 \\
\hline
\end{tabular}

${ }^{a}$ Factor 1: Child-Oriented/Maternal Pleasure; ${ }^{b}$ Factor 2: Quantity of Stimulation; ${ }^{\text {F Factor }}$ 3: Control. 
Factor 1 correlated positively and Factor 2 correlated negatively with MDI $(p<.01)$.

\section{Discussion}

The results of this investigation indicate that potentially important components of maternal behavior may be assessed with the seven-item short form of the Maternal Behavior Rating Scale. This version of the scale compares favorably to the original version both in terms of the components of maternal behavior assessed (i.e., Child Orientedness/ Pleasure and Control) and in terms of the concurrent relationship between these factors and children's level of mental development. The 18-item scale appears to be a slightly more sensitive measure of maternal behavior than the short form, because it assesses an additional component of maternal behavior. In spite of this sensitivity, the full scale does not appear to account for a greater proportion of variability in children's level of functioning.

The main advantage of the short form is that it provides a convenient way to assess maternal interactive behavior on the basis of a relatively small set of items. This convenience, however, may be achieved at the expense of reliability. Factors are clearly more reliable when they are derived from a large number of observations. The potential unreliability of this instrument can be avoided, however, when raters have achieved a high degree of interrater agreement. The scale should not be used as an evaluation instrument until raters have obtained at least $90 \%$ agreement on each of the seven items with another experienced observer. In addition, it is important to continually monitor

Table 5. Factor Analysis of the Short Form of the Maternal Behavior Rating Scale

\begin{tabular}{lcc}
\hline Maternal Behavior & Factor $\mathbf{1}^{\mathbf{a}}$ & ${\text { Factor } \mathbf{2}^{\mathbf{b}}}^{\mathbf{b}}$ \\
\hline Enjoyment & .85 & .12 \\
Sensitivity to State & .88 & -.36 \\
Responsiveness & .82 & -.20 \\
Appropriate Stimulation & .84 & .01 \\
Physical Stimulation & .28 & .70 \\
Directiveness & -.17 & .80 \\
Sensitivity to Interests & .43 & -.83 \\
\hline
\end{tabular}

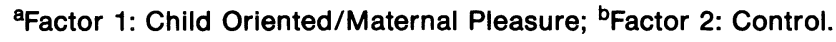


Table 6. Multiple Regression Equations for Maternal Behavior Factors on Standardized MDI

\begin{tabular}{lcccrc}
\hline & Multiple $\boldsymbol{R}$ & $\boldsymbol{R}^{\mathbf{2}}$ & $\begin{array}{c}\text { Partial } \\
\text { Correlation }\end{array}$ & $\boldsymbol{T}$-Stat & $\boldsymbol{p}$ \\
\hline Full Model & .45 & .20 & & & \\
Factor 1 & & & .35 & 2.78 & .008 \\
Factor 2 & & & -.35 & -2.81 & .007 \\
Dummy 1 & & & .24 & 1.86 & .069 \\
Dummy 2 & & & -.06 & -0.48 & .632 \\
\hline
\end{tabular}

the reliability of raters so that shifts in rating criteria do not occur over time.

It should be noted that scores obtained with this scale can only be compared meaningfully to scores obtained from observations of motherchild interaction under the same set of conditions. It is very possible that ratings may vary across different contexts (e.g., home vs. school) or different situations (e.g., toy play vs. no toy play vs. child care) so that different values obtained from observations in different contexts may not reflect changes in maternal style. Although this investigation focused only on mother-child interaction with toys, other situations may be used for assessing mother-child interaction as long as they are constant for all observations.

This scale may be useful only for assessing the effects of intervention programs that have been designed to modify the maternal interactive behaviors that the scale assesses. The MBRS may be insensitive to changes in mothers that are intended by certain forms of intervention. For example, intervention programs that focus on maternal psychological adjustment to a handicapped child may be quite effective in achieving this goal, yet have no impact on the interactive behaviors assessed by this instrument. However, insofar as such intervention programs focus on maternal adjustment as a means for modifying interactive behavior, then the MBRS could be an appropriate assessment instrument.

\section{References}

Ainsworth, M.D.S. (1966). System for rating maternal care behaviors. John Hopkins University, Baltimore.

Antonovsky, H.F. (1959). A contribution to research in the area of mother-child relationship. Child Development, 30, 37-51. 
Assael, D. (1983). Handicapped children's early education program: 1982-83 overview and directory. Washington, DC: Special Education Programs, U.S. Department of Education.

Baldwin, A.L, Kalhourn, J., \& Breese, F.H. (1949). The appraisal of parent behavior. Psychological Monographs, 63 (Whole No. 229).

Blank, M. (1964). Some maternal influences on infant rate of sensorimotor development. Journal of the Academy of Child Psychiatry, 3, 668-687.

Bromwich, R.M. (1978). Working with parents and infants: An interactional approach. Austin, TX: PRO-ED.

Caldwell, B., Heider, J., \& Kaplan, B. (1966). The inventory of bome stimulation. Paper presented at the meeting of the American Psychological Association, New York.

Clarke-Stewart, K.A. (1973). Interaction between mothers and their young children: Characteristics and consequences. Monographs of the Society for Research in Child Development, 36 (6-7, Serial No. 153).

Grossman, H.J. (Ed). (1973). Manual on terminology and classification in mental retardation. Baltimore: Garamond/Pridemark Press.

Kerlinger, F., \& Pedhazur, E. (1973). Multiple regression in bebavioral research. New York: Holt, Rinehart \& Winston.

MacDonald, J.D., \& Gillette, Y. (1984). Turntaking with communication. Ohio State University, Columbus.

Mahoney, G.J., \& Powell, A. (1984). Transactional intervention program. Woodhaven, MI: Woodhaven School District.

Mahoney G., Finger, I., \& Powell, A. (1985). The relationship of maternal behavioral style to the developmental status of organically impaired mentally retarded infants. American Journal of Mental Deficiency, 90(3), 296-302.

Main, M., Tomasini, L., \& Tolan, W. (1979). Differences among mothers of infants judged to differ in security. Developmental Psychology, 15, 472-473.

Meadow, K.P., \& Schlesinger, H.S. (1972). Interaction rating scale for mothers and deaf children. Unpublished manuscript. University of California, San Francisco.

Sameroff, A.J., \& Chandler, M.J. (1975). Reproductive risk and the continuum of caretaker casualty. In F.D. Horowitz (Ed.), Review of child development research (Vol. 4, pp. 187-244). Chicago: University of Chicago Press.

Schaefer, E.S., Bell, R.Q., \& Bayley, N. (1959). Development of a maternal behavior research instrument. Journal of Genetic Psychology, 95, 83-104.

Stover, L., Guerney, B.G., \& O'Connell, M. (1971). Measurements of acceptance, allowing self direction, involvement, and empathy in adult-child interaction. Joumal of Psychology, 77, 233-241.

Whiting, J.W., Child, I.L., Lambert, W.W., Fischer, J.L., Nydegger, C., Nydegger, W., Maretzki, H., Maretzki, T., Minturn, L., Romney, A., \& Romney, R. (1966). Field guide for a study of socialization (Vol. 1). New York: Wiley.

Yarrow, L.J., Rubenstein, J.L., \& Pedersen, F.A. (1975). Infant and environment: Early cognitive and motivational development. New York: Wiley. 


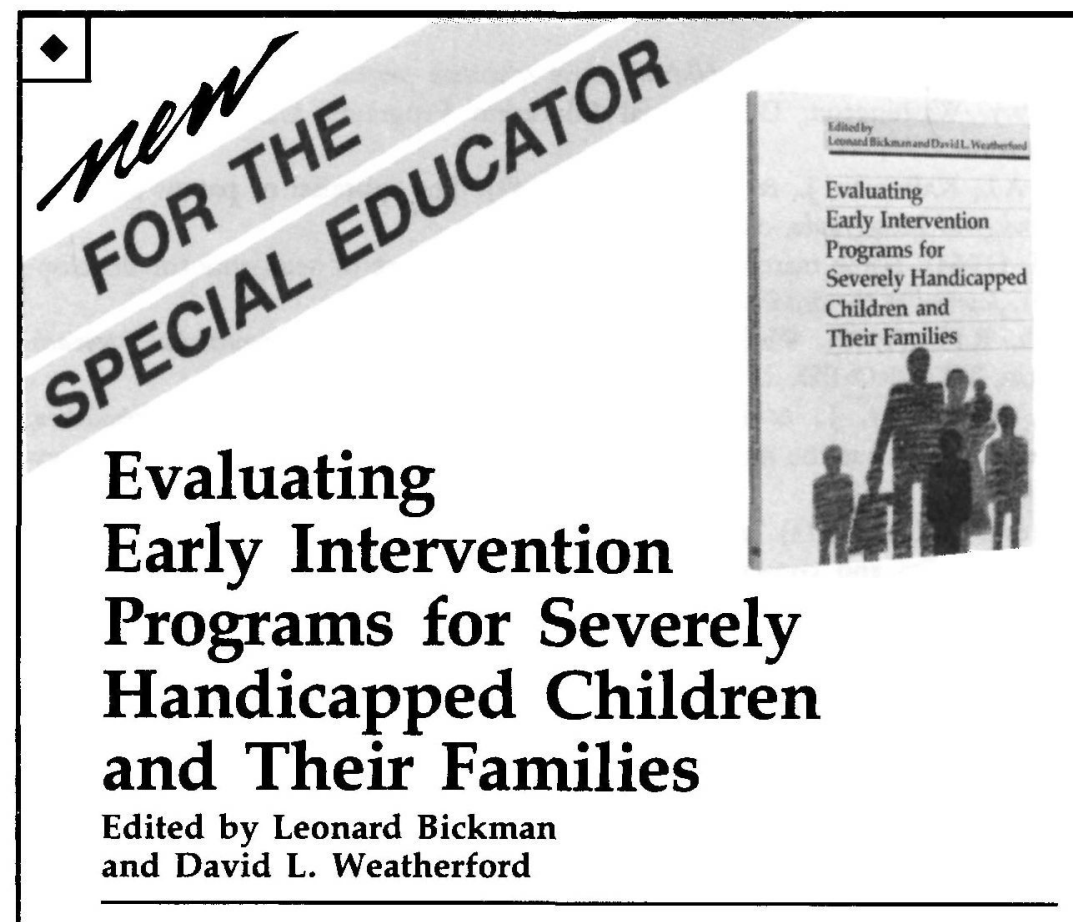

Leading practitioners present practical techniques and approaches for use by special educators, directors, and staff in evaluating their early intervention programs. This compilation is unique because it deals specifically with the severely handicapped, emphasizing the importance of the family in these programs. This guide for practitioners is also an excellent textbook for graduate special education courses dealing with the severely handicapped.

\section{CONTENTS}

1. The Challenge of Evaluating Early 7. Design Issues in Family Impact

Intervention Programs

2. Characteristics and Special Needs of Severely Handicapped

Preschoolers

3. Intervention Programs for Severely Handicapped Infants and Children

4. Overview of the Efficacy of Early Intervention Programs

5. Sources of Evaluation Practice

6. Evaluation Alternatives for Early Intervention Programs
Evaluation Programs

8. Evaluating Educational Processes in Programs for Severely Handicapped Preschoolers

9. The Measurement of Family Functioning

10. The Impact of Evaluation Research on Policymaking

11. The Use of Stakeholders in Planning Evaluations of Intervention Programs

350 pages, 1986

\#1397, illustrated paperback

To order this title and other materials designed specifically for the professional educator, write or call

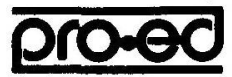

5341 Industrial Oaks Blvd.

Austin, Texas 78733

$512 / 892-3142$

Current catalog available on request. 